\title{
CORRESPONDENCE
}

\author{
Diabetes care: whose responsibility? \\ B Hurwitz, MRCGP, and J Yudkin, MD; \\ R G Pietroni, MRCGP.............. 1000 \\ Fetal malformations in diabetics with \\ high haemoglobin $A_{1 c}$ in early \\ pregnancy \\ M Reid, FRCPGLAS, and others. \\ 1001 \\ Haemoglobin $A_{1 c}$ concentrations in men \\ and women with diabetes \\ E J Hindle, MRCPATH, and others...... 1001 \\ Haemoglobinopathies and glycosylated \\ haemoglobin estimation \\ G Pulman, FIMLs, and others......... 1001 \\ How common are gall stones? \\ H P Rhomberg, MD, and others. . . . . . 1002 \\ Naftidrofuryl and the nitrogen, \\ carbohydrate, and lipid responses to \\ moderate surgery \\ H J G Burns, FRCS; J A Inglis, FRCS, and \\ others . . . . . . . . . . . . . . . . . . . . . 1002
}

$\beta$ Blockade, diuretics, and salt restriction for the management of mild hypertension

G T McInnes, MRCP; Th M Erwteman,

MD, and others............... 1003

Kielland's forceps delivery

C J Carr, frCOG. . . . . . . . . . . . . . . . 1003

Musings of a dean

$R$ A Joske, FRACP. 1003

Comparison of reliability of tests to distinguish upper from lower urinary tract infection

T Sandberg, $M D$, and others; G H C Schardijn, MD, and LW Statius Van Eps, MD . . . . . . . . . . . . . . . . . . 1004

Salivary oestriol to progesterone ratio in relation to spontaneous labour $\mathrm{L}$ Perry, MSC, and others; H H G McGarrigle, MSC, and Gillian C L Lachelin 1004

Different types of neurologist

R H Johnson, FRCP . . . . . . . . . . . . . . 1005
The Warnock report

S F Hayes, BM................... 1006

Costs of teaching hospitals

J R A Mitchell, FRCP............... 1006

Community health doctors need not

"rage and despair"

P Tizard, FRCP, and D Irvine, FRCGP . . . . 1006

Points Do not forget activated charcoal in phenylpropanolamine poisoning (K $\mathrm{T}$

Olkkola and P J Neuvonen); Intragastric

bacterial activity and nitrosation before, during, and after treatment with omeprazole (K G Wormsley); Appropriate technology: respiratory diseases (M

Harries; J P Anderson); Dangers of adding

insulin to intravenous infusion bags $(M \mathrm{~J}$

Curtis and $M$ Singer); Stoved in fractures

(A G de Clercq); Jarisch-Herxheimer reaction in falciparum malaria? (A B G

Laing); Doctors and the Third World

(D Oakley John); Is there a link between

cot death and child abuse? (R R Gordon);

Death of a spouse (V H Needham)..... 1007

We may shorten letters to the editor unless the authors specifically state that we may not. This is so that we can offer our readers as wide a selection of letters as possible. We receive so many letters each week that we have to omit some of them. Letters must be typed with double spacing between lines and must be signed personally by all their authors, who should include their degrees. Letters critical of a paper may be sent to the authors of the paper so that their reply may appear in the same issue.

Correspondents should present their references in the Vancouver style (see examples in these columns). In particular, the names and initials of all authors must be given unless there are more than six, when only the first three should be given, followed by et al; and the first and last page numbers of articles and chapters should be included.

\section{Diabetes care: whose responsibility?}

SIR,-A rapid reading of the two recent articles evaluating general practitioner care of type II diabetics might perplex some general practitioners who are reconsidering the care they provide (22 September, p 726 and 728). Comparison of process and outcome measures in patients looked after in general practice with similar patients retained in the hospital diabetic clinic highlights the following points:

(1) Routine general practitioner care, where no special mechanisms are employed to ensure regular follow up and review, appeared to increase the risk of poorer diabetic control and higher overall morbidity and mortality. In the Cardiff trial only $13.6 \%$ of patients discharged to general practitioner care from the hospital clinic were seen once a year, and of these only one third had a blood glucose estimation taken in the same period.

(2) In the Wolverhampton study ( $p$ 726), well organised care by interested and committed general practitioners (as indicated by the running of miniclinics) resulted in a similar degree of diabetic control to that achieved in a hospital clinic, as judged by retrospective mean blood glucose and glycosylated haemoglobin concentrations or prospective glycosylated haemoglobin concentrations.

Several other studies provide relevant information about current patterns of diabetic care, which we feel add weight to these findings. They also have implications for those of us who are trying to develop a strategy for the community care of these patients.

In 1980 one of us reported on the current patterns of care in an east London health district. ${ }^{1}$ Of 217 diabetic patients attending nine general practitioners in three group practices (without miniclinics) 54\% were not currently attending a hospital diabetic clinic. The frequency of clinical review was substantially lower in these patients than in those attending the hospital clinic, although there was no significant difference in glycosylated haemoglobin concentrations.

Other studies in various parts of the British Isles have also shown that between $45 \%$ and $54 \%$ of diabetic patients do not regularly attend a hospital diabetic clinic and may not visit their general practitioner for regular supervision. ${ }^{2-4}$ It would appear therefore that only about half of known diabetics receive routine general practitioner care even in districts with diabetic hospital clinics. We mus assume the figure to be higher in those 28 districts the British Diabetic Association has recently identified as having no consultan with responsibility for diabetic care (unpublished report to the medical advisory committee of the BDA, 1983).

Together the two $B M \mathcal{F}$ papers give us some measure of the avoidable morbidity and mortality that might follow for diabetics if their care could be better organised and their follow up ensured. Yet only $37 \%$ of patient in Wolverhampton attend practices where a general practitioner runs a miniclinic even after 14 years of encouragement and support from the consultant and hospital clinic. ${ }^{5}$ It is unlikely that a global policy of encouraging general practitioners to set up diabetic miniclinics - particularly in inner cities-will both provide a solution to improving diabetic supervision by general practitioners and at the same time reduce the number of patients attending overcrowded hospital clinics. In any case there are strong reasons to believe that a miniclinic mentality in general practice towards every chronic disease with an appreciable prevalence is both impractical and undesirable.

In Islington we are encouraging a flexible approach to general practice diabetic care. Some practices have set up miniclinics, others are seeing diabetics in normal surgery time, while another proposes a "diabetic day" during which diabetic patients will be booked in to see their own general practitioner and the practice will be geared up (though not exclusively) for diabetic measurements. Yet another proposes a weekly "diabetes hour" alternating between partners during a morning surgery. All these practices have been provided with specially designed 10 year record cards which fit in the general practitioner notes or can be held by the patient.

In neither the Cardiff study nor the Fife study before it, however (unpublished report by A M D Porter of the Kirkcaldy Community Medical Care Project, 1979), did such a record card prove a failsafe device to ensure regular or relevant clinical review. For this reason we are looking at the possibility of creating a district diabetic register and using a centralised computer prompt to both patient and general 
practitioner (with hardware and software provided by the Greater London Council funded London New Technology Network), to encourage clinical review and regular assessment of biochemical control. If, as in the east London study, ${ }^{1}$ most general practitioner supervised patients once attended a hospital diabetic clinic it should be possible to build most of the register from hospital records. The remainder may be provided by general practitioner disease lists and prescription returns for hypoglycaemic drugs and urine testing agents.

Whittington Hospital,
Londoir N19

BRIAN HURWITZ

JOHN YUDKIN

1 Yudkin JS, Boucher BJ, Schopflin KE, et al. The q 1 lity of diabetic care in a London health distr

2 Done' BJ. An audit of the care of diabetics in a group

pr ctice. $\{R$ Coll Gen Pract 1976;26:734-42.

3 Dr 'ctice. $\mathcal{F} R$ Coll Gen Pract 1976;26:734-42. $M$. A community study of diabetes in Oxfordshire. $M$
$\mathcal{R}$. A Coll Gen Pract $1983 ; \mathbf{3 3}: 151-5$.

4 Mulone P. Diabetes mellitus in an Irish general prictice. I Med f 1982;75:116-8.

5 Thorn PA, Russell RG. Diabetic clinics today and tomorrow: miniclinics in general practice. $\mathrm{Br} \mathrm{Med} f$

SIR,-Dr Philip Home and Dr Simon Walford pose a question, "Diabetes care: whose responsibility ?" (22 September 1984), and then fail to answer it. While there has been an encouraging trend towards educating diabetic patients more fully in their own management they cannot be fully independent and need the skills of a practitioner to monitor their disease. It is now beyond doubt that poor control of diabetes leads to a higher long term incidence of microvascular complications. ${ }^{1}$ The practitioner should therefore strive for good control in the diabetic. But who is the practitioner? Is it the hospital specialist, the general practitioner, or both ?

The hospital specialist, somewhat reluctantly, has tended to assume a good deal of the responsibility for the care of the diabetic attending his clinic. Because of the numbers of diabetic patients, however, it is easy for some patients to escape from regular surveillance. A patient who cancels his clinic appointment and does not make another may be lost from follow up altogether. Whose responsibility are these patients? If a patient fails to attend for his clinic appointment then he may be sent another appointment. If he fails to attend on further consecutive occasions then his general practitioner may be notified. Does the general practitioner accept this responsibility to follow up the failed attenders? Who assumes responsibility for those diabetics (half of the general practitioner's diabetic population ${ }^{2}$ ) who do not attend any hospital diabetic clinics?

I believe that as general practitioners provide "personal, primary, and continuing care" 3 then ultimately it is the general practitioner's responsibility. The "collusion of anonymity" 4 that develops with many chronic problems, must not be allowed to develop with diabetics. General practice seems to me to be the ideal setting for managing this chronic illness. The development of miniclinics and shared care diabetic clinics needs to be encouraged. Not all general practitioners are in favour of such clinics for various reasons; for these a minimum alternative is for their practices to keep a register of their diabetic patients. Such a register would not be difficult to set up and maintain. The general practitioner's responsibility would then be to record that all the diabetics on his register are at least receiving regular surveillancewhether in hospital or in general practice.

London W12 8QX

Roger G Pietroni

1 Tchobroutsky G. Relation of diabetic control to development of microvascular complications. Diabetologia 1978;15:143-52.

2 Doney BJ. Audit of care of diabetics in a group practice. $\mathcal{F} R$ Coll Gen Pract 1978;26:734-42.

3 Royal College of General Practitioners. The future general practitioner: learning and teaching. London British Medical Journal, 1972. 4 Balint $M$. The doctor, his patient, and the illness.
London: Pitman Medical, 1957 .

\section{Fetal malformations in diabetics with} high haemoglobin $A_{1 c}$ in early pregnancy

SIR, - We read with interest the paper by Dr K Ylinen and others (11 August, p 345) as we have been carrying out a similar study since August 1984.

We have analysed those patients who had maternal haemoglobin $\mathrm{A}_{1 \mathrm{c}}\left(\mathrm{Hb}_{1 \mathrm{c}}\right)$ estimated on or before 16 weeks' gestation who were seen at a combined obstetric/endocrine clinic. We have analysed the data in a similar manner to Dr Ylinen and others. All the infants born from these pregnancies were examined at the time of delivery, including those from pregnancies that were terminated or stillborn (table). The live born infants were also reviewed at a follow up clinic four to six weeks after discharge from hospital.

Distribution of diabetic pregnancies in relation both to maternal $H b A_{1 c}$ value before 16 weeks of gestation and to occurrence of fetal malformations

\begin{tabular}{|c|c|c|c|c|}
\hline \multirow{2}{*}{$\begin{array}{c}\text { Initial } \\
\text { maternal } \\
\text { HbA }_{1 \mathrm{c}} \\
\text { value } \\
(\%)\end{array}$} & \multicolumn{4}{|c|}{ No $(\%)$ of pregnancies } \\
\hline & Normal $n$ & $\begin{array}{l}\text { Major } \\
\text { alformation }\end{array}$ & $\begin{array}{c}\text { Minor } \\
\text { malformation }\end{array}$ & Total \\
\hline $\begin{array}{l}\geqslant 10 \\
8-9.9 \\
<8\end{array}$ & $\begin{array}{l}18(72) \\
38(66 \cdot 3) \\
55(94 \cdot 9)\end{array}$ & $\begin{array}{l}6(24) \\
5(11 \cdot 4) \\
2(3 \cdot 4)\end{array}$ & $\begin{array}{l}1(4) \\
1(2 \cdot 3) \\
1(1 \cdot 7)\end{array}$ & $\begin{array}{l}25 \\
44 \\
58\end{array}$ \\
\hline Total & & $13(10 \cdot 3)$ & $3(2 \cdot 4)$ & 127 \\
\hline
\end{tabular}

The major malformations were congenital heart disease (6), Potter's syndrome (3) anencephaly (2), and severe skeletal malforations (2). The minor malformations consisted of hypospadias (1), a branchial cyst (1), and a single umbilical vessel (1).

Our results are remarkably similar to those seen in Helsinki despite considerable racial and genetic differences in our two populations Our results therefore support the view of Dr Ylinen and others and of Fuhrmann et al in Germany ${ }^{1}$ that intensified periconceptional treatment of diabetes has the potential to improve the fetal outcome for diabetic patients. We hope tha: these results will stimulate our colleagues in general practice and medical outpatient clinics to refer patients who wish to become pregnant (or those in very early pregnancy) for strict metabolic supervision of their pregnancies to specialised clinics.

MARK REID

D HADDEN

J M G HARLEY

H L HALLIDAY

B G MCCLURE

Royal Maternity Hospital,

Belfast BT 12 6BB

1 Fuhrmann K, Reiher H, Semmler K, Fischer F, Fischer M, Glockner E. Prevention of congenital malformations in infants of insulin dependan diabetic mothers. Niabetes Care 1983;6:213-3.
Haemoglobin $A_{1 c}$ concentrations in men and women with diabetes

SIR,-Mr M H Strickland and others (22 September, p 733) present results which show a significantly higher concentration of haemoglobin $\mathrm{A}_{1 \mathrm{c}}\left(\mathrm{HbA}_{1 \mathrm{c}}\right)$ in women than in men with diabetes.

We have drawn similar conclusions from the analysis of $\mathrm{HbA}_{1}$ by mobile affinity electrophoresis $^{1}$ in specimens collected from 638 subjects (280 women, 358 men) attending a diabetic outpatient department. In our study, women had a mean (1SD) $\mathrm{HbA}_{1}$ concentration (SD) of $10.44(2.92) \%$ total haemoglobin, which was significantly higher than that of men $-9.82(2.84) \%$ total haemoglobin $(p<0.005)$.

Mean glucose concentrations in the women and men were $9.8(5.3) \mathrm{mmol} / 1$ (176 (95) $\mathrm{mg} /$ $100 \mathrm{ml}$ ) and $9.5(4.8) \mathrm{mmol} / \mathrm{l}(171(86) \mathrm{mg} /$ $100 \mathrm{ml}$ ) respectively, which did not differ significantly ( $p>0.05)$.

Serum fructosamine, a measure of glycosylated proteins, was estimated by a method based on that of Johnson et $a l^{2}$ in samples collected simultaneously. Ranges for women and men were $1.44(0.41)$ and $1.42(0.43)$ $\mathrm{mmol} / \mathrm{l}$ respectively, which were not significantly different $(\mathrm{p}>0.05)$.

While the hypothesis that " 'female' haemoglobin can undergo a greater degree of glycosylation compared with that of male diabetic patients" may prove to be true, our evidence from the fructosamine ranges suggests that glycosylation of serum proteins may not be enhanced in a similar way.

Glycosylation of haemoglobin is, however, a relatively slow process $(0.006 \%$ total haemoglobin is glycosylated in $24 \mathrm{~h}$ per $\mathrm{mmol}$ glucose $^{3}$ ) and is thought to reflect blood glucose concentrations over several weeks. Differences in the degree of glycosylation of protein in men and women with diabetes may not be apparent, therefore, in assays such as fructosamine which reflect glycaemia control over shorter periods ( 1 to 3 weeks).

E J HINDLE

G M ROSTRON

J A Gatt

District Laboratory,

Preston Infirmary,
Preston PR1 6PS

1 Ambler J, Janik B, Walker G. Measurement of glycosylated haemoglobin on cellulose acetate membranes by mobile
Clin Chem 1983;29:340-3.

2 Johnson RN, Metcalf PA, Baker JP. Fructosamine: a new approach to the estimation of serum glycosylprotein. An index of diabetic control. Clin Chim Acta 1982;127:87-95.

3 Svendsen PA, Christiansen JJ, Søvgaard U, Nevup J. Synthesis of glycosylated haemoglobin in vivo. Diabetologia $1981 ; 21: 549-53$.

\section{Haemoglobinopathies and glycosylated} haemoglobin estimation

SIR,-Dr R B Paisey and others (4 August, p 279) report that persistent fetal haemoglobin may cause falsely high glycosylated haemoglobin concentrations measured by agar gel electrophoresis. We have recently encountered a patient for whom an additional haemoglobin peak was noted during determination of glycosylated haemoglobin concentrations by agar gel electrophoresis which led to the previously unsuspected diagnosis of haemoglobinopathy (HbC trait).

The patient is a 69 year old black man who was born in Belize but had been resident in the UK since 1941 . He had malaria at the age of 7 but was 